\title{
Temporal distribution of Typical Petroleum Pollutants in oil-polluted Soil of Gudao Region
}

\author{
Xiaohua Ren ${ }^{\mathrm{a}}$, Xiaoli Sun ${ }^{\mathrm{b}}$ \\ Weifang University of Science and Technology, Shouguang, 262700, China \\ arenxiaohua2008@163.com, bsunxiaolizi@163.com
}

Keywords: oil pollution, total petroleum hydrocarbons, PAHs, temporal distribution.

Abstract. Four soil surface samples were collected and analyzed with GC-MS method to study the temporal distribution of typical petroleum pollutants in the oil-polluted soil of Gudao Region.The results showed that the concentrations of five typical petroleum pollutants increased with the increase of oil well exploitation years. The TPHs concentrations were $22.90 \mathrm{~g} / \mathrm{kg}, 16.77 \mathrm{~g} / \mathrm{kg}, 2.90 \mathrm{~g} / \mathrm{kg}$ and $0.81 \mathrm{~g} / \mathrm{kg}$ in the soils near the oil wells exploited in 1970s, 1980s, 1990s and 2000s, respectively, which were all above the remediation standards. The soils contaminated by PAHs around the oil wells exploited in 1970s, 1980s and 1990s were all classified as "heavily contaminated", and the soil polluted by PAHs near the oil well exploited in 2000s was fallen under "weakly contaminated" classification. More importantly, the results could provide basic data for pollution monitoring and oil-polluted soil remediation.

\section{Introduction}

The rapidly economic development has brought a significant enhancement in the rate of petroleum exploration, petroleum production utilization and the related industries rising. Meanwhile, the petroleum exploration process inevitably causes serious environmental pollution. For example, as important petroleum pollutants, total petroleum hydrocarbons (TPHs) and polycyclic aromatic hydrocarbons (PAHs), have drawn the attention of the related researchers due to their mutagenic and carcinogenic potential [1, 2]. However, most studies in the Yellow River Delta focused on the distributions of heavy metals, $\mathrm{N}$ and $\mathrm{P}[3,4]$. A few studies on the distributions of hydrocarbon pollutants $[5,6]$ have been undertaken, but rarely on aliphatic hydrocarbons such as TPHs, PAHs and n-alkanes in the oilfield [7], which have great significance to pollution control and soil remediation.

The paper aims to elucidate the temporal distribution characteristics of the typical petroleum pollutants in oil-polluted soil based on the analysis of the concentrations in soils near oil wells with different exploited years, and find out the possible reasons affecting the distributions of these pollutants. Finally, the results could provide scientific data basis for pollution control and oil-polluted soil remediation.

\section{Materials and Methods}

\section{Study Area}

The study area was situated in Gudao Region of Shengli Oilfield (the second biggest oilfield in China), north of the Yellow River Delta (Fig. 1). Gudao town is a new developing oil-industry town based on oil exploitation, which has a long oil exploitation history of more than 40 years and a short urbanization history of about 20 years. The average annual temperature of the study area is $12.1{ }^{\circ} \mathrm{C}$, and the annual precipitation is approximate $580 \mathrm{~mm}$. The soils in the study area are mostly fluvo-aquic and coastal solonchaks (World Reference Base for Soil Resources). 


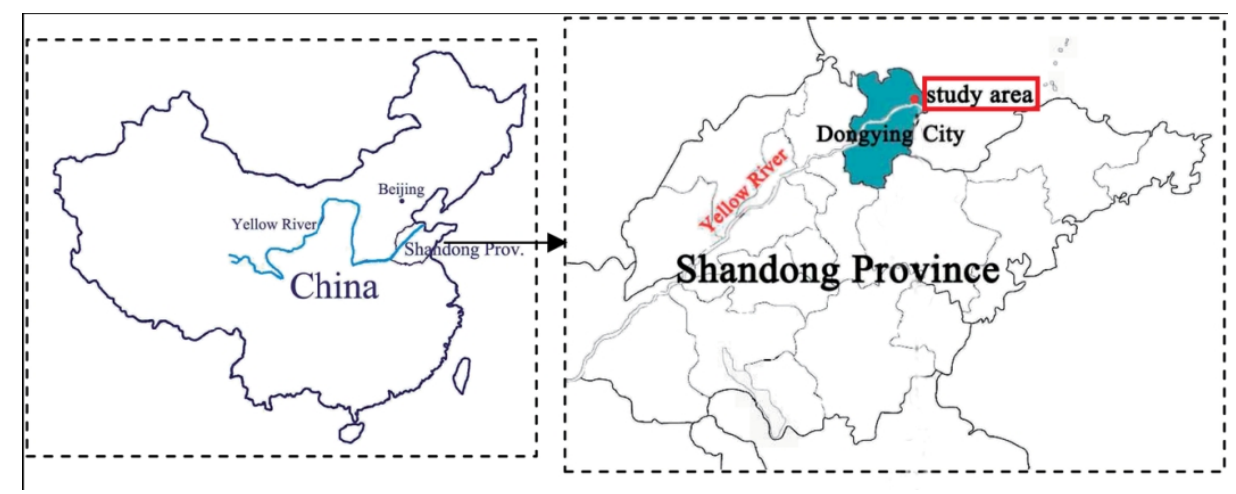

Fig. 1 the location of the study area

\section{Sampling Procedure}

In order to explicate the temporal distribution characteristics of typical petroleum pollutants, four surface soil samples were collected in July, 2013 near oil wells where the soils were polluted by crude oil.

From the development history of the Gudao oil region, the exploitation times of the oil wells could be divided into four periods: 1970s, 1980s, 1990s, and 2000s. Four surface soil samples were collected at $1 \mathrm{~m}$ sites around the oil wells exploited in 1970s, 1980s, 1990s, and 2000s, respectively. For each sample, firstly, five subsamples of similar weights with about $1 \mathrm{~kg}$ were collected with a plastic scoop and a stainless steel shovel. Secondly, the subsamples were mixed together homogeneously. Finally, the weight of the mixed sample was decreased to be about $1 \mathrm{~kg}$ with the quarter method to improve the sample representativeness[8]. The soil samples were stored in plastic bags.

\section{Sample Analysis}

The soil samples were dried at room temperature and then purified by discarding the plant roots and stones. The soil sample (15 g, dry weight) were Soxhlet extracted using $300 \mathrm{ml}$ dichloromethane for 24 h. Activated copper and zeolite were added to remove the elemental sulfur. After extraction, the extract was concentrated to a volume of about 2-3 ml. The extract was evaporated and weighed, and $\mathrm{n}$-hexane was added to the extract to precipitate the asphaltene, finally the extract was evaporated and weighed again. The total petroleum hydrocarbons (TPHs) content was the difference between the two weights. The extract was solvent-exchanged into $20 \mathrm{ml}$-hexane to reduce the volume to about 1-2 ml with a rotary vacuum evaporator. PAHs and n-alkanes were fractionated by $40 \mathrm{ml}$ dichloromethane/n-hexane (v/v 1/1) and $25 \mathrm{ml}$ n-hexane using a 2:1 silica gel/alumina column, respectively. The PAHs fraction and n-alkanes fraction were then condensed to $1 \mathrm{ml}$ by rotary vacuum evaporator and finally to $0.2 \mathrm{ml}$ under a gentle gas stream of high purity nitrogen, respectively.

The PAHs were analyzed by gas chromatography coupled to mass spectrometry (GC-MS) (Agilent/6890N-5973N, Agilent Co., USA) with helium as carry gas. The n-alkanes were analyzed with gas chromatography (GC-2014, Shimadzu Co., Japan). The BTEX components were determined with a purge-and-trap sample concentrator (Eclipse 4660, OI analysis instrument Co., USA ) in combination with gas chromatography. The sulfur was determined using high frequency IR carbon-sulfur spectrometer (CS-878A, Sichuan JingKe Instrument Manufac turing Co., Ltd., China).

\section{Quality Assurance and Quality Control (QA/QC)}

Method blanks (solvent) and spiked blanks (standards spiked into solvent) were conducted for quality assurance and quality control. The relative standard deviations and recoveries of BTEX, n-alkanes and PAHs were in range of 4.6-14.3\% and 83.2-99.7\%, 2.5-14.1\% and 76.5-102.3\%, and $1.8-12.5 \%$ and 75.8-98.5\%, respectively. The detection limits of BTEX, n-alkanes and PAHs were in range of $0.132-0.679,3.2-19.5$ and $2.3-23.7 \mu \mathrm{g} / \mathrm{kg}$, respectively. Besides, the relative standard deviation and detection limit for sulfur was $4.9 \%$ and $0.013 \mathrm{~g} / \mathrm{kg}$, respectively. 


\section{Results and Discussion}

Five typical petroleum pollutants, total petroleum hydrocarbons (TPHs), polycyclic aromatic hydrocarbons (PAHs), n-alkanes, BTEX (Benzene, Toluene, Ethylbenzene and Xylenes) and sulfur, were chosen to be the representatives for their toxicity, persistence and representativeness in the study.

The relation between the concentrations of typical petroleum pollutants and the oil wells of different exploitation years was shown in Fig. 2.

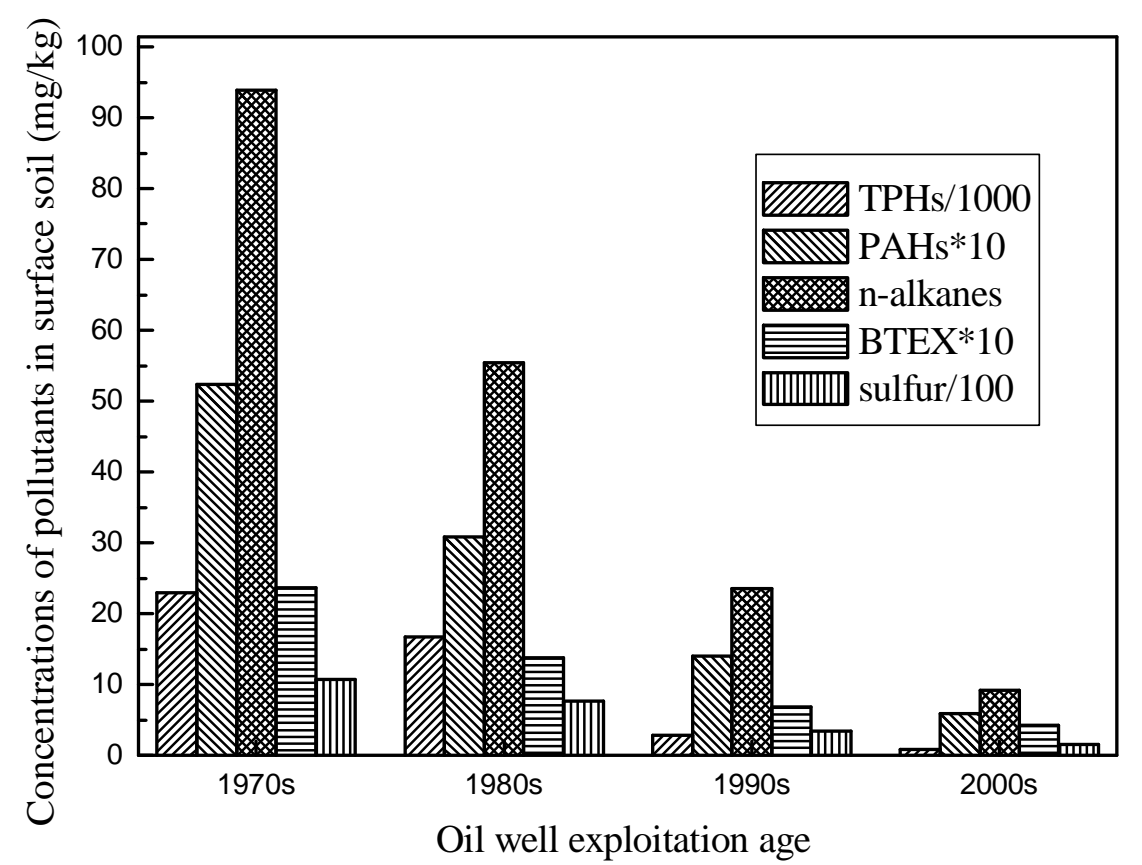

Fig. 2 The concentrations of typical petroleum pollutants at surface sites near the oil wells of different exploitation ages

As illustrated in Fig. 2, the concentrations of the five typical petroleum pollutants increased with the increase of the oil well exploitation years.

For TPHs, the highest concentration of $22.90 \mathrm{~g} / \mathrm{kg}$ was found in the surface soil around the oil well exploited in 1970s, and the concentration in the surface soil around the oil well exploited in 2000s was lowest, but as high as $0.81 \mathrm{~g} / \mathrm{kg}$. This result was consistent with the previous study of Han et al. [9] that the TPHs concentrations was higher in petroleum-contaminated soil around old oil-well than new oil-well. Therefore, it could be concluded that the TPHs contents were significantly influenced by the oil exploitation process. Generally, the TPHs content in soils not contaminated by petroleum was about $1-10 \mathrm{mg} / \mathrm{kg}$. It can be noted that the TPHs concentrations in the soil around the oil well exploited in 1970s was more than 2000 times higher than the background value, and the TPHs concentrations around the oil well exploited in 2000s was more than 80 times higher than the background value. The results suggested that the soils around the four oil wells were all heavily polluted by TPHs. According to the remediation standards for soils contaminated by TPHs established by Oklahoma ( $500 \mathrm{mg} / \mathrm{kg})$ and by Canada ( $450 \mathrm{mg} / \mathrm{kg}$ ), the soils around the four oil wells were all needed to be remedied.

For PAHs, the concentrations in surface soils near the oil wells exploited in 1970s, 1980s, 1990s and 2000s were 5234.59, 3087.52, 1396.28 and 588.52 $\mu \mathrm{g} / \mathrm{kg}$, respectively. Maliszewska-Kordybach [10] classified the soil contaminated by PAHs to four levels, shown in Table 1 . The classification threshold (200, 600 and $1000 \mu \mathrm{g} / \mathrm{kg}$ ) was obtained from the monitored concentrations in European soils and from an estimation of human exposure risks [11]. Obviously, the soils near the oil wells exploited in different years were all contaminated by PAHs. It can be seen that the PAHs contents at the sampling sites near oil wells exploited in 1970s, 1980s and 1990s were all classified as "heavily contaminated". The soil around the oil well exploited in 2000 s was fallen under the "weakly contaminated" 
classification. Previous study by Trapido [12] reported that the background PAHs concentration (no anthropogenic origin) was about $100 \mu \mathrm{g} / \mathrm{kg}$ dry weight. Moreover, the results by Edwards [13] showed that an endogenous PAHs content would be $1-10 \mu \mathrm{g} / \mathrm{kg}$, which comes from biosynthesis and forest fires. Therefore, the soil in this study area were almost contaminated by PAHs through anthropogenic activities.

Table 1 Classification of soil contamination by PAHs [10]

\begin{tabular}{cc}
\hline Class of soil contamination & PAHs $(\mu \mathrm{g} / \mathrm{kg} \mathrm{d.} \mathrm{w.)}$ \\
\hline Not contaminated & $<200$ \\
Weakly contaminated & $200-600$ \\
Contaminated & $600-1000$ \\
Heavily contaminated & $>1000$ \\
\hline
\end{tabular}

The n-alkanes contents of $93.87,55.48,23.55$ and $9.19 \mathrm{mg} / \mathrm{kg}$ were found in the surface soil around the oil wells developed in 1970s, 1980s, 1990s and 2000s, respectively. It can be noted that the n-alkanes concentrations increased significantly with the exploited years.

Similarly, the BTEX concentration distribution in surface soils near oil wells of different exploited years was as following: 1970s >1980s >1990s > 2000s. The concentrations of specific BTEX components were shown in Table 2. As noticed in Table 2, the toluene concentration in the surface soil was highest among the six components and the four exploited years, and the second highest concentration was found for benzene.

Table 2 the concentrations of BTEX components in surface soils near oil wells of different exploited years $(\mu \mathrm{g} / \mathrm{kg})$

\begin{tabular}{lllllll}
\hline exploited years & benzene & toluene & ethylbenzene & o-xylene & m-/p-xylene & BTEX \\
\hline $1970 \mathrm{~s}$ & 645.68 & 763.52 & 489.87 & 148.75 & 315.66 & 2363.48 \\
$1980 \mathrm{~s}$ & 388.73 & 419.84 & 268.02 & 92.43 & 207.91 & 1376.93 \\
$1990 \mathrm{~s}$ & 173.21 & 227.35 & 141.58 & 50.31 & 93.45 & 685.9 \\
$2000 \mathrm{~s}$ & 102.18 & 149.14 & 83.54 & 31.68 & 61.87 & 428.41
\end{tabular}

For sulfur, the concentrations in surface soils near the oil wells exploited in 1970s, 1980s, 1990s and 2000s were $1073.08,761.54,345.77$ and $15.62 \mathrm{mg} / \mathrm{kg}$, respectively. It could be noticed that the sulfur content was correlated with the TPHs content, indicating that the main source of sulfur in surface soil near the oil well was oil pollution.

\section{Conclusions}

The temporal distribution of typical petroleum pollutants in oil-polluted soil of Gudao Region was investigated. The methods of GC, GC-MS and purge-and trap-GC were applied to analyze the petroleum pollutants. The results achieved were as follows:

(1) The concentrations of the five petroleum pollutants increased with increasing the oil well exploited years;

(2) For TPHs, the highest concentration of $22.90 \mathrm{~g} / \mathrm{kg}$ was found in the surface soil around the oil well exploited in 1970s, and the lowest concentration was in the surface soil around the oil well exploited in $2000 \mathrm{~s}$, but as high as $0.81 \mathrm{~g} / \mathrm{kg}$, indicating that the soils near the four oil wells were all heavily polluted by TPHs.

(3) The soils near the oil wells exploited in 1970s, 1980s and 1990s contaminated by PAHs were all fallen under "heavily contaminated" classification, and the soil near the oil well exploited in 2000s was classified as "weakly contaminated".

(4) The sulfur concentration was correlated with the TPHs concentration, which suggested that the main sulfur source in surface soil near the four oil wells was oil pollution. 


\section{Acknowledgements}

This work was supported by ministry of environment production's special funds for scientific research on public causes No. 201109022 and the Scientific Research Funds for Yong Scholars of Weifang University of Science and Technology (No sdlgy2013w003).

\section{References}

[1] L. Hu, Z. Guo, J. Feng, Z. Yang and M. Fang, Distributions and sources of bulk organic matter and aliphatic hydrocarbons in surface sediments of the Bohai Sea, China, Mar. Chem. 113 (2009) 197-211.

[2] K.T. Benlahcen, A. Chaoui, H. Budzinski, J. Bellocq and P.H. Garrigues, Distribution and sources of polycyclic aromatic hydrocarbons in some Mediterranean coastal sediments, Mar. Pollut. Bull. 34 (1997) 298-305.

[3] J. Chen, M. Taniguchi, G. Liu, K. Miyaoka, S. Onodera, T. Tokunaga and Y. Fukushima, Nitrate pollution of groundwater in the Yellow River delta, China, Hydrogeol. J. 15 (2007) 1605-1614.

[4] J. Song, Transferable phosphorus in sediments of the Huanghe River estuary's adjacent waters, Chin. J. Oceanol. Limn. 19 (2001) 81-86.

[5] H. Yamei, M. Zheng, Z. Liu and L. Gao, Distribution of polycyclic aromatic hydrocarbons in sediments from Yellow River Estuary and Yangtze River Estuary, China, J. Environ. Sci-China 21 (2009) 1625-1631.

[6] X. Luo, C. Liu and M. He. Distribution and origin of polycyclic aromatic hydrocarbons(PAHs) in sediment from the Yellow River, Res. Environ.Sci. (In Chinese) 18 (2005) 48-50.

[7] C. Wang, W. Wang, S. He, J. Du and Z. Sun, Sources and distribution of aliphatic and polycyclic aromatic hydrocarbons in Yellow River Delta Nature Reserve, China, Appl. Geochem. 26 (2011) 1330-1336.

[8] SEPAC, Environmental Quality Standard for Soils (In Chinese), Chinese environmental sciences press, Beijing, 1995.

[9] D. Han, S. Jiang and D. Wen, Vertical Distribution of TPHs in Petroleum-contaminated Soil of Liaohe Oilfield, Chin. J. Soil Sci. (In Chinese) 39 (2008) 932-934.

[10] B. Maliszewska-Kordybach, Polycyclic aromatic hydrocarbons in agricultural soils in Poland: preliminary proposals for criteria to evaluate the level of soil contamination, Appl. Geochem. 11 (1996) 121-127.

[11] S. Paterson and D. Mackay. A model illustrating the environmental fate, exposure and human uptake of persistent organic chemicals, Ecol. Model. 47 (1989) 85-114.

[12] M. Trapido, Polycyclic aromatic hydrocarbons in Estonian soil: contamination and profiles, Environ. Pollut. 105 (1999) 67-74.

[13] N.T. Edwards, Polycyclic aromatic hydrocarbons (PAH's) in the terrestrial environment-a review, J. Environ. Qual. 12 (1983) 427-441. 